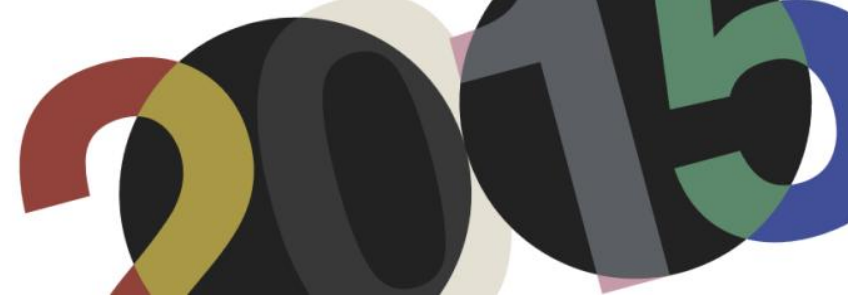

DOI: http://dx.doi.org/10.4995/LC2015.2015.610

\title{
Bajo la Luz. Buscando la luz
}

\author{
I. de Viar Fraile \\ Escuela Técnica Superior de Arquitectura de Donostia-San Sebastián
}

\begin{abstract}
Resumen: Le Corbusier fue un gran buscador. Un buscador de luz. Tras un primer periodo de búsqueda halló su arquitectura cúbica y blanca y luego, después de la Guerra y quince años sin construir, Le Corbusier inició un nuevo camino, una nueva búsqueda de la luz en su arquitectura; mucho más plena. En este segundo periodo el trabajo con la luz y con la sombra, sobre todo con la sombra, como mecanismo plástico, escultural, es muy intenso. Trabajó con la luz por medio de dos sistemas: la" interposición" y la "captación" (captura). El sistema de la "interposición” lo realizó mediante los Brise-Soleil, en un principio y luego, con mucha mayor contundencia, mediante los "edificios parasol" construidos como fachadas interpuestas. El sistema de la "captación”, más reducido, lo realizó por medio de lucernarios y grietas, buscando la luz, siempre con diferentes orientaciones. Por último decir que un arquitecto tan material como Le Corbusier construyó con lo inmaterial, con la luz, tejido de sus obras. Los edificios tratados son unos pocos, los principales, todos ellos de su segunda época.
\end{abstract}

Abstract: Le Corbusier was a great searcher. A light searcher. Afterwards a first period of searching he founded his cubic and white architecture and after the Word War II and fifteen years without erecting up a building, Le Corbusier restarted a new path, a new search for the light in his architecture, much broader. In this second age, the work with the light and with the shadow, mostly with the shadow, as plastic and sculptural mechanism is very deep. He worked with the light via two systems: "interposition" and "capture". The mechanism of "interposition" was developed by Le Corbusier by means of the BriseSoleil, at the beginning, and later, much more strongly, by means of the "parasol-sun shade buildings", erected like front façades. The "catching" system, done on a smaller scale, was made by the construction of several skylights and gaps, searching for the light and always with different orientations. Finally say that a material architect as Le Corbusier was, he constructed with the immaterial light, weave of his works. The buildings studied are a few, all of them part of second period and they are the core of Le Corbusier's buildings.

Palabras clave: Luz, Sombra, Buscar, Interposición, Captación, Silencio. Keywords: Light, Shadow, Search, Interposition, Capture, Silence.

\section{Buscar}

"El que encuentra ha buscado mal” Rutger Kopland ${ }^{1}$

Hay tanto en la obra de Le Corbusier; volumen, color, pintura, escultura, mediterráneo, arte moderno y mundo clásico, Turquía, Suiza o Grecia, máquina y paquebote, concha y naturaleza, cielo, blanco, negro, función, ángulo recto, curvas, ciudad, promenade, rampas y planos, espacio, recinto, pilotis, horizonte, hombre, proporción, medida y modulor, color y béton brut, periodismo y propaganda, moral, Italia, Alemania, África y Estados Unidos, textura; búsqueda, viaje, sol, luz, sombra y mar...tantas cosas.

Le Corbusier fue un perpetuo buscador. Buscó, como buen buscador, con el fin de no encontrar. Jordi Savall ${ }^{2}$ explica como el término recercada designa (en la obra de Diego Ortiz) la intención compositiva de recercar, es

\footnotetext{
${ }^{1}$ Pascal Quingard en su libro "Las escaleras de Chambord", mediante el protagonista Eduard, recita ese verso del poeta Holandés Rutger Kopland.

${ }^{2}$ Jordi Savall escribe sobre las recercadas en la introducción del disco sobre música de Diego Ortiz.
} 
decir, buscar de nuevo. Una de las principales búsquedas y preocupaciones de Le Corbusier fue el trabajo con la luz solar y la sombra, la búsqueda de la plástica. Buscó de nuevo, siguió buscando. Alan Le May escribió en 1954 su más famosa novela, The Searchers, que luego adaptó John Ford. En un momento, cuando Amos (Ethan/Wayne en la película) y Mart, llegan a la reserva de Fort Sill, el agente Hiran Appleby, un cuáquero de pelo canoso, les informa:

"Ningún grupo de comanches se mueve tan furtivamente como los Nawyecky. Uno de los nombres por los que les conocen el resto de los comanches es el de «Los-que-nunca-llegan-a-donde-se dirigen». No lo van a creer. Lo que les gusta es confundir y mentir acerca de su destino, y parten en una dirección, luego retroceden y se desvían. Lo hacen como hábito, sin ningún motivo aparente. "”

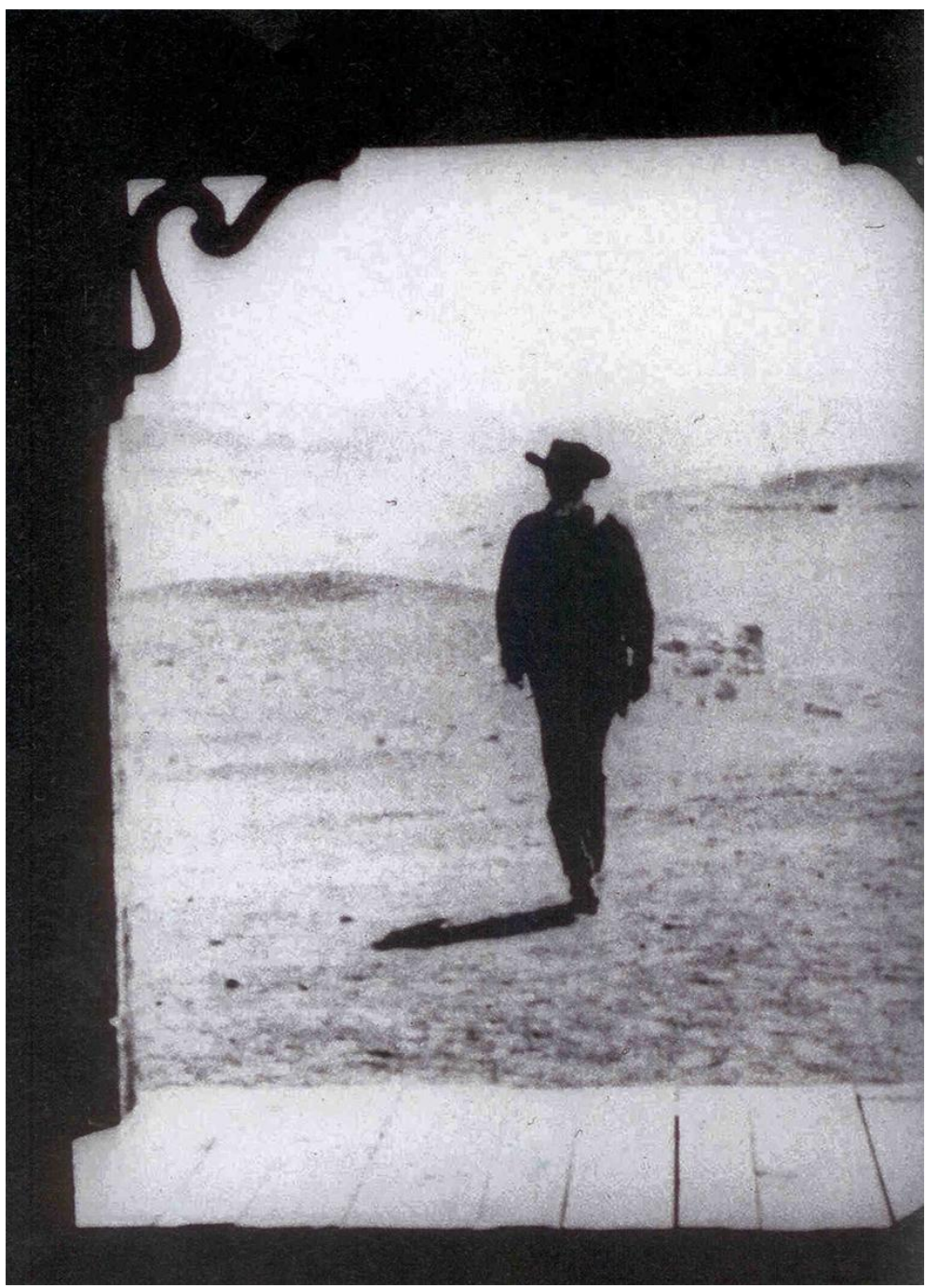

1. Imagen de "Centauros del desierto". John Ford. 1956. Años de Chandigarh, Ronchamp y La Tourette

${ }^{3}$ Alan Le May, Centauros del Desierto. 
Al final cuando Amos y Mart cabalgan, todavía sin encontrar a Debbie, de regreso a casa, escribe Le May:

"El hogar, para ellos, era más un rumbo que un lugar. Era como la marca de un topógrafo que está en el mapa pero no en la tierra: se está al sur de allí, y luego se cabalga hacia allí, y tras un tiempo estás al norte de allí, pero nunca se está exactamente allí, porque no existe tal cosa; el hogar tan sólo existe en la mente de uno."

La búsqueda, la luz, el rumbo, más que el lugar guiaron a Le Corbusier. El trabajo de Le Corbusier nacido en la opaca suiza- no puede entenderse si no es bajo la luz del sol, en un mundo de luces y sombras.

Es difícil situar en el tiempo las obras de Le Corbusier. Sus obras se alargaron en el tiempo y sus libros son temáticos, alejándose de una cronología lineal. Sin embargo defino dos épocas básicas y diferenciadas, dos periodos de trabajo y búsqueda muy claros y definidos en su obra. Antes y después de la Segunda Guerra Mundial. Y los defino en su relación con el trabajo con la luz. Hay una primera preocupación, en el periodo anterior a la guerra, por la luz como definidora de volúmenes, en superficie, construyendo con planos y luces frías. Y un periodo de madurez, desarrollado tras la guerra, después de un largo periodo sin construir. Son años de madurez, cercano a los sesenta; son los años donde el trabajo plástico es más intenso, consciente y original.

\section{Fascinación (Tecnológica) y Volúmenes Bajo la Luz.}

El interés de Le Corbusier por el trabajo con la luz, sobre la relación de la arquitectura con la luz se manifiesta desde el principio de sus trabajos y escritos. En "Vers une Architecture", Le Corbusier lanza tres advertencias a los señores arquitectos. En la primera, donde aparece su famosa frase definiendo la arquitectura como el juego sabio de los volúmenes bajo la luz, dice también:

"Nuestros ojos están hechos para ver las formas bajo la luz"،

Le Corbusier forma parte de la larga línea que funda la modernidad, originada en la visión poética de Edgar Allan Poe, recibida en Europa por Charles Baudelaire y que llega a las vanguardias a través de Stéphané Mallarmé, Raymond Roussel o Marcel Duchamp. Fernand Leger explica muy bien la fascinación y el descubrimiento por las obras de la ingeniería del momento, por los avances y el diseño técnico, contaba:

"Fernad Léger cuenta que posiblemente en aquel mismo año de 1912 visitó una exposición de tecnología aeronáutica en compañía de Constantin Brancusi y Marcel Duchamp. Volviéndose hacia su amigo Brancusi, parece que Duchamp dijo: «La pintura ha muerto. ¿Quién podrá hacer algo mejor que esta hélice? Dime, serías capaz de hacerla? "6

Esta seducción, este descubrimiento, esta nueva visón -comprensible, ya que la belleza de las máquinas, del mundo nuevo, es en aquellos años indiscutible-, es asumida por las vanguardias contaminando en poco tiempo a

\footnotetext{
${ }^{4}$ Alan Le May, Centauros del Desierto

${ }^{5}$ Le Corbusier, 1923, en "HACIA UNA ARQUITECTURA" lanza; TRES ADVERTENCIAS A LOS SEÑORES ARQUITECTOS, I, PRIMERA ADVERTENCIA: EL VOLUMEN

La arquitectura es el juego sabio, correcto y magnífico de los volúmenes reunidos bajo la luz. Nuestros ojos están hechos para ver las formas bajo la luz: las formas y los claros revelan las formas. Los cubos, los conos, las esferas, los cilindros o las pirámides son las grandes formas primarias que la luz revela bien; la imagen de ellas es clara y tangible, sin ambigüedad. Por esta razón son formas bellas, las más bellas. Todo el mundo está de acuerdo con esto: el niño, el salvaje y el metafísico. Es la condición esencial de las artes plásticas.

${ }^{6}$ Citado por Janis Mink en su libro sobre Duchamp
} 
todo el mundo del arte. Fascinación de las vanguardias también por el primitivismo, por el arte Africano. Dos descubrimientos -lo más primitivo y lo más tecnológico-, que fundamentaron buena parte del credo del arte de aquellos años. Le Corbusier, tras su viaje iniciático al primitivo oriente, buscaba, y encontró en estas dos sugerencias apoyos para su arquitectura. Por ejemplo, casi diez años después hacía suyas las revelaciones de Duchamp declarando su atracción por las máquinas ${ }^{7}$. También el cubismo, la pureza geométrica y las avanzadas ideas gestadas en la República de Weimar ayudaron en este cocktail para "fijar" la nueva arquitectura que Le Corbusier buscaba en esos primeros años de iniciación.

Sus ideas estaban claras ya desde su paso por Italia. En el camino de vuelta de su viaje a Oriente, a finales de 1911, escribió:

«Clamo por la geometría elemental; estoy poseído por el color blanco, el cubo, la esfera, el cilindro y la pirámide. Los prismas se elevan y se equilibran entre sí, estableciendo ritmos... bajo el sol del medio día los cubos se aplanan convirtiéndose en una superficie, en el crepúsculo un arco iris parece elevarse de las formas. Por la mañana son reales, arrojan luz y sombra y se perfilan claramente como un dibujo..... ${ }^{8}$

Y encontró sus primeras casas manifiesto, sus edificios de la primera época en París, cubistas, puristas, racionales, iniciando y propulsando la nueva arquitectura. Edificios blancos, exteriores, formados mediantes planos, volumétricos, fríos, casi gélidos; suizos. Esta primera arquitectura de Le Corbusier trabaja con la luz de una forma distante, exterior, creando volúmenes (puros bajo la luz).

\section{Viajes, Mediterráneo y Cambio.}

\section{“Todas las luces convergen al mar" Edmond Jabés ${ }^{9}$}

Los viajes fueron fundamentales en la vida y en la obra de Le Corbusier y como escribía Francis Bacon ${ }^{10}$, los viajes, en la época de la juventud, son parte de la educación; en la vejez, parte de la experiencia. La educación fue su viaje a oriente; la experiencia sus muchos viajes posteriores. Le Corbusier fue un gran viajero.

Le Corbusier había iniciado una carrera fulgurante y llena de éxitos y reconocimiento; en menos de diez años sus encargos como arquitecto fueron creciendo desde su primer proyecto "racionalista", el atelier de Ozenfant (1922) hasta los proyectos de los años 30; el Pabellón Suizo, el inmueble Clarté o la casa en la calle Nungesser et Coli (1930/32). Después de estos proyectos, cuyas obras se alargan hasta los primeros años treinta, Le Corbusier no vuelve a construir hasta el encargo de la Unidad de Habitación en Marsella en 1945, ya posicionado como gran figura internacional. En todo este tiempo, larguísimo periodo para cualquier arquitecto y más para una figura como Le Corbusier, no construye (salvo pequeños temas y la colaboración con Niemeyer y Costa en Brasil en 1936) y redirige sus energías a la pintura (en su estudio de su nueva casa), a un intenso trabajo explicando sus ideas, con conferencias y viajes y con múltiples propuestas urbanas (Barcelona, Ginebra, Estocolmo, Villa Radieuse y tantas otras). En estos años convulsos en Europa y en Francia, donde (ahora es fácil posicionarse) los extremos y excesos de la derecha y la izquierda estaban muy cerca, Le Corbusier busca grandes clientes en los diversos gobiernos. En 1928 recibe el encargo del edificio Centrosoyuz en Moscú, poco después

\footnotetext{
${ }^{7}$ En 1923 publicó Vers une Architecture y empezó las publicaciones de L`Esprit Nouveau en 1920.

${ }^{8}$ Juan Antonio Cortés en su artículo "La caja y el parasol, dos modelos recurrentes en la obra de Le Corbusier". Le Corbusier, Catalogo exposición, 1987. Le Corbusier adopta la seducción que Cezanne anticipaba a principios de siglo (cita33)

${ }^{9}$ Edmond Jabés, El libro de las preguntas.

${ }^{10}$ Francis Bacon, De la Sabiduría Egoísta.
} 
está cerca de afiliarse al Frente Popular, también intentó "vender" sus proyectos e ideas al régimen fascista de Mussolini, en 1937 fue nombrado Caballero de la Legión de Honor y finalmente, durante la ocupación se instaló en Vichy en 1941. En 1942 el régimen de Vichy le encargó realizar una serie de propuestas urbanísticas en Argelia pero en $1942^{11}$-al no conseguir trabajo del gobierno de Vichy- volvió a instalar su estudio en Paris, estableciendo lazos con la izquierda y fundando ASCORAL, un colectivo de Arquitectos e Ingenieros. Y es, en esa época oscura, convulsa, de vaivenes políticos, de difícil supervivencia y equilibrio, cuando Le Corbusier fragua su nueva arquitectura.

Durante este tiempo, casi quince años sin construir, Le Corbusier redescubre el sol, el mar y lo mediterráneo conoció y le impresionó la Kasbah de Argel- y realizó muchos viajes; Brasil y Argentina en 1929 y en 1935 Estados Unidos (visitando entre otros lugares Columbia, Yale, Princeton y Harvard). Años de búsqueda, una nueva y fructífera búsqueda. Buscar de nuevo, otro inicio. Dice George Steiner hablando de Incipit, incipiente:

"La inicial, en la cual el término significa comienzo y primacía, actúa como fanfarria; enuncia la máxima de Platón-de ninguna manera evidente-de que en todas las cosas, naturales y humanas, el origen es lo más excelso." 12

Esta nueva búsqueda, este nuevo inicio, diseña una nueva arquitectura, más interesante, personal y fructífera; ya no busca la rabiosa actualidad o el manifiesto, busca un mundo personal, una poética propia; sentida, humana, mediterránea y táctil.

Es el periodo bien conocido y descrito, por ejemplo Charles Jenks ${ }^{13}$ lo llamó "Other Languages of Architecture 1946-65”, que inicia a los cincuenta y ocho años, después de la Guerra.

\section{Más entero}

Juan Antonio Cortés explicaba muy bien las dos arquitecturas de Le Corbusier; caja y parasol.

"Se ha invertido en estos últimos edificios el planteamiento de los que consideramos en primer lugar. La estructura de losas y pilares - la estructura Dom-ino- no queda ya contenida dentro de un volumen geométrico regular y cerrado. Esa estructura sale al exterior como elemento abierto y destacado del edificio y bajo ella se sitúan los volúmenes que contienen los espacios habitables. Parece haberse cerrado así, en este recorrido desde las primeras casas de los años veinte hasta el Centro de Le Corbusier de Zúrich - completado en 1967 dos años después de la muerte del maestro_, el ciclo de la relación entre la estructura, que se ajusta al esquema Dom-ino, y el cerramiento, que sigue la idea de cuerpo platónico. De ser una superposición de losas sostenidas por una serie de pilares y estar contenida dentro del volumen ideal del cerramiento, la estructura ha pasado a exhibirse al exterior como gran marquesina o parasol que da sombra —real o figurada- a dicho cerramiento, descompuesto ahora en un conjunto de volúmenes y de superficies varias. Ha desaparecido con ello la pureza geométrica en que quedaban contenidas las casas de los años veinte, con su envolvente elemental, nítida, cerrada, que albergaba en su interior una gran complejidad plástica y espacial. Pero han aparecido en cambio las formas abiertas, exteriormente activas, de los parasoles, que pasan a dar una nueva escala y un nuevo orden simbólico al edificio "14

\footnotetext{
${ }^{11}$ París es liberada en agosto de 1944

${ }^{12}$ George Steiner, Gramáticas de la Creación

${ }^{13}$ Charles Jenks fija cuatro periodos: Jeanneret's School for Le Corbusier 1887-1916, The Hero of the Heroic Period $1917-$ 28, A War with reaction 1928-45 y por último, Other Languages of Architecture 1946-65.

${ }^{14}$ Juan Antonio Cortés en su artículo "La caja y el parasol, dos modelos recurrentes en la obra de Le Corbusier". Le Corbusier, Catalogo exposición, 1987.
} 
En la película de Víctor Erice, "El sol de membrillo", Antonio López conversando con Enrique Gran, pintor y amigo, recuerda como un profesor en la Academia de San Fernando al acercarse a sus pinturas y comentarle su trabajo, le decía:

-Más entero.

Y después explica Antonio López como -cuando era estudiante- no entendía aquello que su profesor quería significar, pero no se atrevía a preguntar. En 1992, él y Enrique Gran, lo entienden y no lo explican por obvio. Así es la obra de posguerra de Le Corbusier en su segundo periodo; "más entera". Mucho más entera. Más radiante, luminosa y también llena de sombras.

Hablaré y lo haré genéricamente, ya que forman un conjunto bastante compacto y coherente, de algunos edificios de la segunda época de Le Corbusier ${ }^{15}$, los más emblemáticos; 1'Unité en Marsella (1945-1952), la Casa Carrutchet (1949), los proyectos para la India (en 1951 empieza el plan Urbanístico de Chandigarh), Ronchamp (1951-1955), La Tourette (1953-1960). También incluyo la Fábrica Duval en Saint Dié (1946), terminada antes que la "l'Unité", por ser el edificio donde aparecen por primera vez los Brise-Soleil. Insisto, todos ellos iniciados después de los cincuenta y ocho años y después de tiempo sin construir. Edificios y proyectos desarrollados alternativamente, superpuestos en el tiempo, desarrollados durante veinte años, hasta la muerte de Le Corbusier en 1965 con setenta y ocho años.

$\mathrm{Su}$ arquitectura tiene ahora textura, es más cercana a lo táctil. Por un lado es más mediterránea, próxima a la artesanía, la cerámica o el esparto (vía en la que incidió Sert). Pero al mismo tiempo aparece el béton brut como material plástico que resuelve todo (mirando las grandes obras de la ingeniería, las presas o torres de refrigeración) y se aleja de la máquina de habitar. La luz es más vibrante, oblicua, temblorosa, curva, densa. Aleteante.

Escribía María Zambrano:

"Se muestra ahora el claro como espejo que tiembla, claridad aleteante que apenas deja dibujarse algo que al par se desdibuja. Y todo alude, todo es alusión y todo es oblicuo, la luz misma que se manifiesta como reflejo se da oblicuamente, más no lisa como espada. Ligeramente se curva la luz arrastrando consigo al tiempo". ${ }^{16}$

\section{Luz y Arquitectura}

Escribía Le Corbusier para Ronchamp:

"La clave

es la luz

y la luz esclarece las formas

$Y$ estas formas tienen

una potencia emotiva

por el juego de las relaciones

inesperados, sorprendentes ${ }^{, 17}$

\footnotetext{
${ }^{15}$ Hay otra serie de edificios y proyectos sin realizar que considero un poco ajenos al discurso y que no incluyo por diversas razones; por la escala, la intensidad, etc. Tampoco incluyo o trato otras muchas propuestas construidas en la segunda época mencionada, como son: El cabanon (1950), la casa Jaoul (1951-55), la casa de Brasil (1957), el pabellón Philips (1958), el museo de Arte Occidental de Tokio (1959), el Carpenter Center (1959-1962), la Iglesia de Firminy (1960), la Casa del Hombre en Zurich (1963), las otras Unidades de Habitación o varios edificios en Chandigarh.

${ }^{16}$ Zambrano, María, Claros del Bosque.
} 
Para Le Corbusier la clave es la luz, sigue siendo la luz. En el largo camino entrelazado entre la arquitectura y la luz, entiendo que los arquitectos se han enfrentado a la lucha con la luz de dos formas básicamente; construyendo las arquitecturas que se protegen y las que la buscan la luz. Porque el mundo -y su arquitectura- se puede dividir de nuevo en dos; una parte tiene un exceso de luz y la otra déficit, lo que origina dos modelos de arquitectura; una se defiende de la luz (mediterránea), la otra, atrapa y condesa la escasa luz (nórdica), con todo lo que ello ha supuesto para la arquitectura y la manipulación de la luz. Le Corbusier participa de los dos mundos.

Podemos entonces decir que en la arquitectura (histórica) hay dos sistemas de trabajar con la luz. Los edificios escultura (exterior; templo griego), que funcionan hacia fuera, por medio de la interposición y trabajando las sombras y los edificios cofre (interior; Roma, románico, gótico), que funcionan como espacios con una determinante cualidad de luz, buscando atrapar, captar y manejar la luz en su interior y que utilizan el sistema de la captación. Curiosamente, cuando la pintura es más plana, los interiores son más ricos espacialmente; la luz tamizada, espesa y coloreada de las Iglesias y Catedrales medievales es el ejemplo. En el renacimiento la luz es racional (en la pintura y en la arquitectura). El barroco excava las posibilidades de la luz, en la pintura, la escultura y la arquitectura. ¡Que maravillosa la captación de la luz barroca en la arquitectura! Luego, la arquitectura se hace más racional, más clara, iluminada y tal vez, más plana y no es hasta el movimiento moderno (tardío) cuando la luz vuelve a ser voluntariamente captada y manipulada por los arquitectos ${ }^{18}$. Le Corbusier investigó y llevó hasta el límite muchas de las posibilidades. Por un lado trabajó el sistema tradicional de luz y sombra, la interposición y también trabajó el sistema de la captación. En 1960, definía la arquitectura como una secuencia de espacios "iluminados". Escribía como primero dibujaba un personaje, lo situaba en la casa y le hacía descubrir su volumen, tal forma de habitación y sobre todo tal cantidad de luz que entra por la ventana o el panel de cristales. Avanza: otro volumen, otra llegada de luz. Más lejos, otra fuente luminosa; más lejos aún, inundación de luz y penumbra a un lado. Habla en términos de luz natural, no hay mención a luz artificial, aunque también trabajó al final de su carrera, con la luz proyectada -eléctrica- la más nueva opción. En los mismos años desarrolló, quizás con demasiado adelanto, un trabajo experimental con luz artificial (proyecciones, música, espectáculo multimedia y poema electrónico de Edgar Varèse) en el pabellón Phillips de la Expo de Bruselas de 1958, que interesante sin duda, no es ahora objetivo.

\section{LUZ}

"Yo empleo, ya se habrán dado ustedes cuenta, abundantemente la luz; la luz es para mí base fundamental de la arquitectura. Yo compongo con la luz" Le Corbusier. ${ }^{19}$

Pensar sobre la luz en Le Corbusier es hablar de la luz natural, del sol, es hablar de la ausencia de luz. La descripción más interesante es la que define la luz como aquello que hace visibles los objetos.

Una definición técnica nos dice que la luz, es energía electromagnética radiante, que puede ser percibida por nuestros ojos. La luz presenta una naturaleza compleja: dependiendo como la observemos se manifestará como

\footnotetext{
${ }^{17}$ Le Corbusier: Textos y Dibujos para Ronchamp. Edición de Joan Petit, 1965, pocos meses antes de la desaparición de Le Corbusier.

${ }^{18}$ Con excepciones como Soane o Labrouste.

${ }^{19}$ Le Corbusier, hacia 1960. Citado por José Baltanás. Le Corbusier, "Précisions sur un état présent de lárchitecture et de l'urbanisme".
} 
una onda o como una partícula; tiene masa y se curva, y es atraída por la masa de los planetas. Veamos algunas fascinantes definiciones científicas, a las que es difícil escapar. Me interesa la luz como fenómeno poético, plástico, sin embargo la física también tiene una visión atractiva. Podemos hacer un glosario ${ }^{20}$ de los principales términos científicos:

Luz: El ojo humano sólo puede detectar una pequeña franja de todo el amplio espectro de ondas electromagnéticas. Las longitudes de onda visibles del espectro electromagnético, van desde los $400 \mathrm{~nm}$ (violeta) hasta los $700 \mathrm{~nm}$ (rojo). La luz esta compuesta de rojo, naranja, amarillo, verde, azul, añil y violeta. Cuando un rayo de luz atraviesa un prisma, se descomponen las franjas que lo constituyen y configuran un arcoíris de colores llamado continuo o espectro continuo.

Ondas electromagnéticas: Generadas por cargas eléctricas que oscilan, las ondas electromagnéticas difieren en su longitud de onda y en su frecuencia. Pero todas ellas, no obstante, se desplazan, en el vacío, a la misma velocidad, que gira en torno a los $300.000 \mathrm{Km} / \mathrm{s}$. Ésta es la velocidad de la luz y constituye la confirmación experimental de que la luz es una onda electromagnética.

Espectro electromagnético: Todo el rango de las ondas electromagnéticas, que va desde las ondas de radio, hasta la radiación infrarroja, la luz visible, la radiación ultravioleta, los rayos X y los rayos gamma.

La luz es roca (balín) y ola, roca y ola indistintamente:

“La publicación del artículo de Bohr (los electrones dan vueltas al rededor del núcleo del átomo en una serie de orbitas predeterminadas y al hacerlo no pierden energía, 1913) marcó el principio del fin de la visión clásica del mundo, pero lo peor estaba por venir. Einstein había demostrado que la luz presentaba dos naturalezas: corpuscular, como los balines disparados en una feria, y ondulatoria, como las olas de un estanque. En 1924 el francés Louis de Broglie, completó esta visión al afirmar que los balines no tenían que comportarse siempre como balines; también podían comportarse como olas de un estanque." Mark Kac ${ }^{21}$

Los receptores $^{22}$ de estas ondas o balines son nuestros ojos (el ojo no lanza, recibe, es la mirada la que proyecta, la que lanza y ve, y mide y piensa y entiende, la mirada pensante). En nuestra retina existen unas células que transforman los impulsos eléctricos y mandan señales al cerebro, traduciendo la luz (y el color dependiendo de la longitud de onda) y definiendo así los objetos. De hecho nuestros ojos han evolucionado para hacer mejor uso de la radiación solar y hacer los objetos visibles a la luz. El cielo y el mar son azules por ser el espectro del azul el más amplio, el que más vemos. Los primeros primates desarrollaron en su evolución adaptaciones complejas ya que requerían nuevas habilidades cazadoras y recolectoras. Se vieron obligados a explotar fuentes de alimento por encima del nivel del suelo, lo que produjo cambios físicos de importancia; los ojos pasaran a una posición frontal, proporcionando una visión binocular que permitía navegar por un espacio tridimensional (mejor para atrapar presas) y desarrollaron la visión del color, que posibilitaba diferenciar las coloridas frutas del espeso verde y poder así consumir una amplia gama de alimentos.

Pero volvamos a lo realmente interesante; la capacidad de la luz de hacer visibles los objetos. El desocultamiento o la magia de la visibilidad son sus cualidades. Sin luz no hay nada. La verdad es aquello que se sitúa en la luz,

\footnotetext{
${ }^{20}$ Cita de Manjit Kumar sobre Niels Bohr.

${ }^{21}$ Miguel Ángel Sabadell cita a Mark Kac.

${ }^{22}$ Los objetos, nubes de electrones, protones y neutrones enlazados, absorben o reflejan la luz de un emisor con diversa intensidad. La luz rebota con distintas longitudes de onda y es interpretada por nosotros como formas, texturas y colores. Es nuestro cerebro, mediante los impulsos traducidos desde el ojo, quien es capaz de construir e interpretar -a partir de esas longitudes de onda y esos vacíos o sombras- un mundo tridimensional y en color.
} 
lo que se pone en escena; la antigüedad griega definía la verdad desvelada como aquello que se coloca a plena ${ }_{l u z}{ }^{23}$. La condición de la luz de hacer visibles las cosas, la verdad, se debe en gran medida a la sombra, que sitúa las cosas sobre un fondo, dando profundidad y volumen a los objetos (percepción tridimensional). Luz es Sombra.

\section{Sombra (y LUZ)}

“Bajo las bóvedas, miro

la oscuridad y no veo

la oscuridad: veo luz

en su negación”

Antonio Gamoneda ${ }^{24}$

Hablar de la luz en Le Corbusier es también hablar de su vaciado, de la sombra. Los arquitectos no creamos la luz, producimos sombras ${ }^{25}$, y Le Corbusier es el maestro moderno de la sombra.

La luz y la sombra son opuestos y complementarios, ya que sin sombra la luz nada desvelaría. La luz es todo, la sombra es la nada que la completa. Luz es presencia, aparición, consciencia; sombra es distancia, desaparición, ocultación, inversión. Pero no hay presencia sin ausencia, ser y no-ser se engendran el uno al otro ${ }^{26}$. Le Corbusier llama, en algún momento, luz enferma a la oscuridad.

La sombra es la oscuridad, la falta de luz, más o menos completa, como nos dice el diccionario (RAE). Nos dice también el diccionario que la sombra es la proyección oscura que un cuerpo lanza en el espacio en dirección opuesta a aquella por donde viene la luz; sugerente. Es, también, la imagen oscura que sobre una superficie cualquiera proyecta un cuerpo opaco, interceptando los rayos directos de la luz. En definitiva, la sombra es una zona donde la luz es bloqueada por un objeto interpuesto ${ }^{27}$, más o menos opaco, una imagen oscura proyectada. La sombra es también la alteración de la proyección de una figura, estirada o comprimida, es móvil y elástica, y es la sombra (solar), al alargarse o acortarse, al acentuarse o desvanecerse, al vibrar y girar, la que da movimiento a los objetos, siguiendo el recorrido del sol.

Pero la sombra en Le Corbusier es mucho más. Si la luz desvela la imagen, la sombra es la ficción, el fantasma, que suscita emoción, empatía y terror, más allá de los que provocan la percepción y empatía verdaderas. Es la puesta en escena de lo inauténtico, de lo fraudulento. Las sombras chinescas o el teatro de sombras contienen una doble ficción, ya que se interponen objetos sobre una pantalla, tras la fuente de luz, de manera que vemos la sombra de la sombra. Así son los edificios parasol. Escribe George Steiner

"Las sombras se alargan al atardecer, buscando el contacto con la tierra" 28 ,

\footnotetext{
${ }^{23}$ Michel Serres, Atlas.

${ }^{24}$ Antonio Gamoneda, Canción Errónea.

${ }^{25}$ O captamos y tamizamos la luz.

${ }^{26}$ Lao Zi. Tao Te King.

${ }^{27} \mathrm{Si}$ lo que nuestro ojos ven son ondas electromagnéticas rebotadas en los objetos con diferente longitud (color), la interposición, la creación de sombras, se produce al impedir, negar, que la luz llegue y rebote.

${ }^{28}$ George Steiner, Gramáticas de la Creación, escribe también: "Hoy en día, las actitudes occidentales -nótese la muda presencia de la luz matutina en la palabra «occidental», los reflejos, los cambios de percepción pertenecen al mediodía y al atardecer."
} 
La sombra de le Corbusier (solar, negra) se estira y se comprime, es móvil y elástica, y, al alargarse o acortarse, al acentuarse o desvanecerse, al vibrar y girar, da movimiento a los edificios siguiendo el recorrido del sol.

La sombra en Le Corbusier tiene gran cantidad de matices. Hay sombras espesas, negrísimas, de gran densidad; hay sombras con un contorno muy definido o sin un límite claro, hay sombras verticales y sombras alargadas, hay sombras con vibración y sombras petrificadas, hay sombras matizadas y muy claras, hay sombras sobre blanco y sombras sobre negro, hay sombras mediterráneas o nórdicas. Las sombras puede ser opacas o veladuras.

Una peculiaridad de las sombras solares es que no son "en color", son, podríamos decir, en blanco y negro ${ }^{29}$ y si la sombra se produce por interposición de un objeto, es la luz la que es mutilada. No es extraño, por tanto, el atractivo del cine y la fotografía en blanco y negro, su reducción a la luz (blanca) y la sombra (negra), basta con recordar la sombra portentosa y crepitante del conde Orlok en Nosfertau $^{30}$ (1922), en las sombras perfiladas de Ivan el Terrible ${ }^{31}(1945)$, las expresionistas luces y sombras de Orson Welles o las tamizadas de Josef Von Sternberg y, como no, los claroscuros del cine negro (negro por la temática, negro por la sombras) desde Jacques Tourneur hasta Fritz Lang. Recordar también la larga tradición de la fotografía en blanco y negro, iniciada con los primeros contactos de Fox-Talbot y la magia de su misterio hasta la actualidad. El color apareció en la fotografía muy pronto (color aditivo en 1861 o transparencias al carbón en tres colores en 1870), pero no se desarrollo hasta mucho más tarde, casi un siglo, quizás por la falta de interés. Tanizaki ${ }^{32}$ a principios de los años treinta era consciente de la cualidad de la sombra y de la perdida que la utilización indiscriminada de la plana luz eléctrica podía suponer. Algo parecido a lo que Marcel Schwob apreciaba unos años antes, disfrutando de la lectura y de la atractiva luz de una vela, artificial, finita y cambiante:

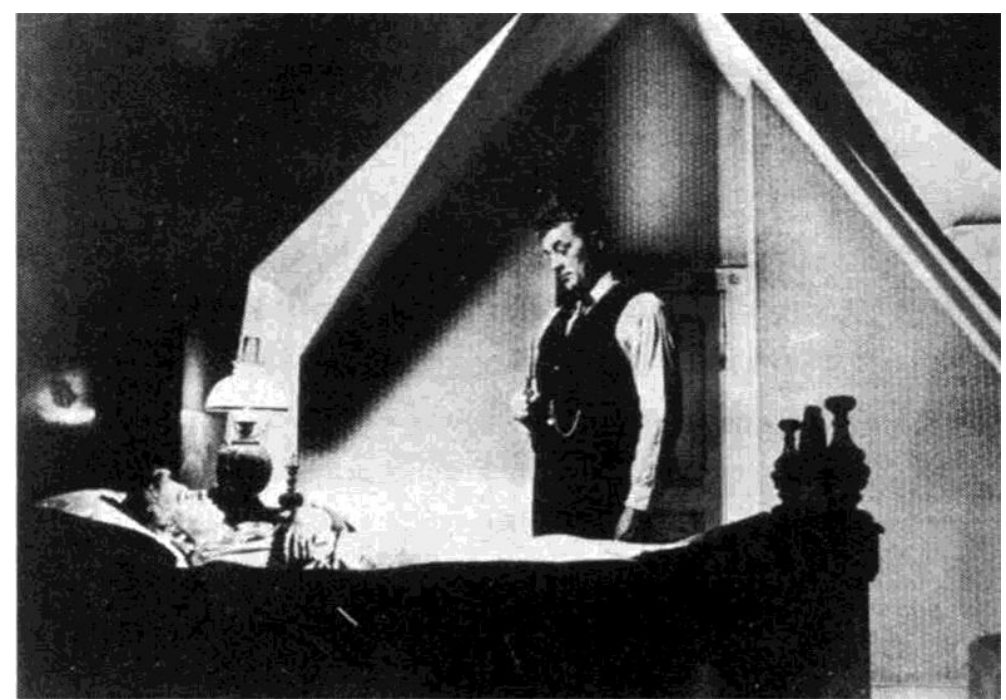

2. Imagen de "La noche del cazador". Charles Laughton. 1955.

\footnotetext{
${ }^{29}$ Luz blanca; suma de todas. Sombra negra; negación de todas.

${ }^{30}$ F.W. Murnau.

${ }^{31}$ Sergei Eisenstein.

32 Junichiro Tanizaki, El elogio de la sombra (1933). En su conocido libro decía: Cuando sustituyeron la lámpara por un candelabro aún más oscuro y pude observar las bandejas y los cuencos a la luz vacilante de la llama, descubrí en los reflejos de las lacas, profundos y espesos como los de un estanque, un nuevo encanto totalmente diferente.
} 
"Leer en la cama es un placer de seguridad intelectual mezclado con bienestar... Recuerdo la página más interesante de la gran novela que devoraba antes de dormir, a la noche, hacia los quince años, en el momento en que se enturbia, se ensombrece, se borra, mientras la vela consumida hasta el final crepita, palpita azul en el candelabro y se apaga" Marcel Schwob ${ }^{33}$

Sentimiento de la vibración de las luces y las sombras, de cierta pérdida, que también compartía Cezanne:

“Vivimos bajo la férula de los capataces. Es el reino de los ingenieros, la república de las líneas rectas... ¿Hay acaso una sola línea recta en la naturaleza, dígame?... ¿Dónde esté Aix, mi Viejo Aix, las callejuelas del barrio viejo, la hierba entre las piedras de la calzada, las lámparas de petróleo...? Sí, la iluminación a petróleo, en lugar de vuestra cruda electricidad que viola el misterio, mientras que nuestras antiguas lámparas lo doraban, lo cocían, lo habitaban al estilo de Rembrandt..."34 Volviendo sobre el entrelazado necesario entre la luz y la sombra, Victor I. Stotchita habla de una fábula que sin duda nos suena familiar, "La maravillosa historia de Peter Schlemihl”, de Adelbert von Chamisso (1813). En la historia, Schlemihl, situado entre Fausto y Peter Pan, vende su sombra al diablo por una bolsa de oro inagotable. Descubre entonces que la sociedad -y la mujer a la que ama- rechazan a un hombre sin sombra, pasando el resto de su vida vagando por el mundo dedicado -curiosamente- a la exploración científica. El diablo convence a Schlemihl mediante las siguientes palabras:

“-Durante el corto tiempo que he tenido la suerte de encontrarme a su lado... si me permite decírselo, señor, he podido contemplar con auténtica e indecible admiración la bellísima sombra que da usted en el suelo, esa magnífica sombra que, sin darse cuenta, con un cierto noble descuido... arroja ahí a sus pies. Y ahora, perdóneme la atrevida pretensión: ¿No podría quizás sentirse inclinado a cedérmela? ’35

El diablo se fija en "la bellísima sombra que $d a$ usted en el suelo", y que con descuido arroja a sus pies. Algo tan natural se convierte en excepcional, como excepcional es perder la sombra y el consiguiente rechazo de la sociedad a un "hombre sin sombra". ¿Por qué? Quizás por que no exista, porque un hombre sin sombra representa la ignorancia de las reglas, un objeto sin sombra pertenece a lo imposible, a la ficción.

\section{Blanco y Negro Vs Color}

¿Y el color? Si las sombras solares son en blanco y negro, son ausencia. ¿Qué ocurre entonces con el color?

Para mi Le Corbusier es en blanco y negro, funciona muy bien. Quizá sea porque sus libros son básicamente en blanco y negro, por que la luz y la sombra son también en blanco y negro. Quizás porque el color, el color en planos, los colores suaves del principio, los colores fuertes del final, sean tan importantes en su obra. Quizás porque el color reacciona con el incoloro hormigón.

\footnotetext{
${ }^{33}$ Marcel Schwob en "El Terror y la piedad".

${ }^{34}$ Paul Cézanne, Leer la naturaleza. Palabras recogidas por Joachim Gasquet, Cézanne, 1921. Curiosamente Cezanne también anticipa, literalmente, la visión volumétrica de Le Corbusier. En un carta a Emile Bernard (Aix, 15 de abril de 1904) escribía: Permítame repetirle lo que le decía aquí: trate a la naturaleza mediante elcilindro, la esfera, el cono, todo puesto en perspectiva, de forma tal que cada lado de un objeto o de un plano se dirija hacia un punto central. Las líneas paralelas al horizonte dan la extensión, ya sea de una sección de la naturaleza...Las líneas perpendiculares a ese horizonte dan la profundidad. Ahora bien, la naturaleza, para nosotros los hombres, es más profundidad que superficie, de ahí la necesidad de introducir en nuestras vibraciones de luz, representadas por los rojos y los amarillos, una cantidad suficiente de azules, para hacer sentir el aire.

${ }^{35}$ Adelbert: Von Chamisso, La Maravillosa historia de Peter Schlemihl.
} 
Hay varios colores en la arquitectura de Le Corbusier. Los apagados y pálidos colores mediterráneos, colores del Monte Athos, los colores fuertes y planos de la etapa cúbica, los enérgicos colores y murales de posguerra y los colores de la luz; de la Tourette o Ronchamp. Y hay otros, como los colores de sus policromías arquitectónicas, de los catálogos y muestras para los papeles pintados Salubra (1931).

\section{Interposición y Captación. Brisa y Sonido}

Hay dos sistemas de los que ya he hablado previamente y que Le Corbusier utiliza trabajando con la luz. Uno exterior, la interposición y otro interior, la captación, que construyen edificios escultura y edificios cofre.

Pensar en el recorrido de la luz es pensar en el inicio. Desde su origen el mito de la pintura nos remite a la luz, a la sombra y al contorno (límite). El alfarero Butades, según una idea de su hija, perfiló sobre arcilla la sombra del rostro del amado de esta, proyectada a la luz de una vela, realizando así el primer dibujo a línea. Así del plano, de la superficie de la sombra, surge la línea. Pero también las más antiguas pinturas rupestres, el origen mítico de la pintura, nos remite al mecanismo de la sombra, más aún a la interposición. En el Panel de las Manos negativas (Galería de las Manos) de la cueva e Chauvet (30.000-10.000 a.C., las más antiguas pinturas rupestres conocidas) o la "Cueva de las Manos" (Patagonia, 9.300 a. C.) juegan con el contorno y el negativo, obtenido al soplar los pigmentos sobre una mano adherida a la pared. El primer gesto, la primera acción. El negativo.

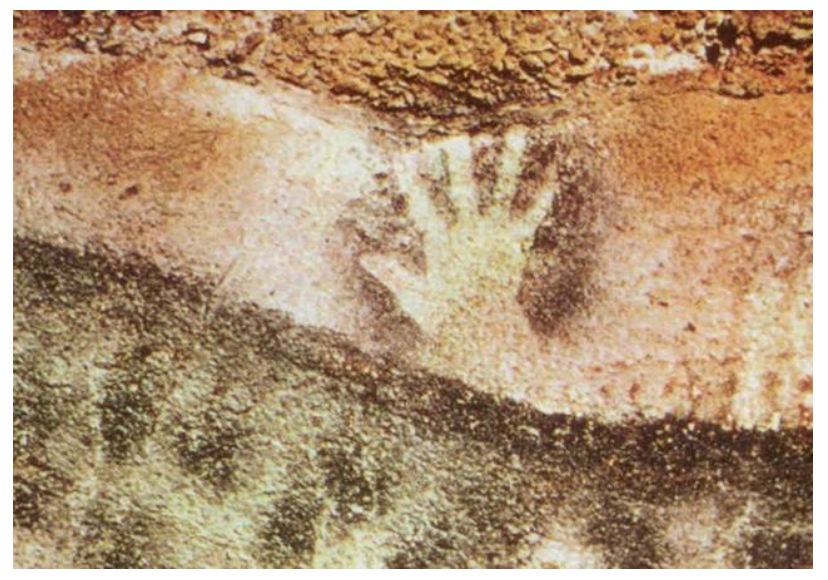

3. Imagen de la Cueva de Peche-Merle, Francia. Detalle Mano. Aproximadamente 25.000 a.C.

Este primer mecanismo es la interposición; lo utiliza Le Corbusier de dos formas. Primero (y quizás tímidamente), mediante el Brise-Soleil, después con absoluta rotundidad con los edificios parasol. Si la sombra es la proyección oscura que un cuerpo lanza en el espacio en dirección opuesta a aquella por donde viene la $l u z$, Le Corbusier proyecta oscuridad sobre sus fachadas secundarias. La sombra, y esto es fundamental, se derrama, bien sobre el propio objeto -que la recibe-, modelándolo, bien sobre un fondo, el vacío de la fachada secundaria. Su sección eficaz es una silueta bidimensional; la inversión del objeto que bloquea la luz. El BriseSoliel, elementos creadores de sombras, pasa de ser un mecanismo adherido a la fachada a convertirse en edifico, llegando a constituirse como verdaderas construcciones autónomas superpuestas al volumen principal, los edificios parasol. Estos edificios parasol se construyen delante las fachadas secundarias, se interponen, entre la luz y el edificio y crean, además, una distancia infinita entre lo exterior y lo interior. El trabajo con la sombra es portentoso en Le Corbusier, es un trabajo griego. Es ahora cuando realmente aparece el mediterráneo en la arquitectura de Le Corbusier, el tacto del sol mediterráneo, la piedra, la rugosidad y la vibración: Grecia. Las 
luchas del sol y la sombra. El mármol se convierte en hormigón, las estrías de las columnas en planos. Las columnas, el peristilo, son los edificios parasol, la cella la fachada secundaria.

El Brise-Soleil ${ }^{36}$, aparece por primera vez como tal en el edificio para las Manufacturas Duval, Saint-Dié, en 1946-51. Experimentos anteriores son en la torre de alquiler en Argel (1933) o el Ministerio de Educación y Salud Pública en Brasil (1936). Realmente no importa. Pronto, paralelamente, aparecen los edificios parasol, el primero en Argentina, en la casa del Doctor Carruchet, en 1949.

Son edificios Brise-Soleil:

- La fábrica de manufacturas en Saint-Dié, Francia (1946/51)

- La Unité d'habitation de Marsella, Francia (1946/52)

- El convento de La Tourette, los “ondulatorios”, Francia (1957/60)

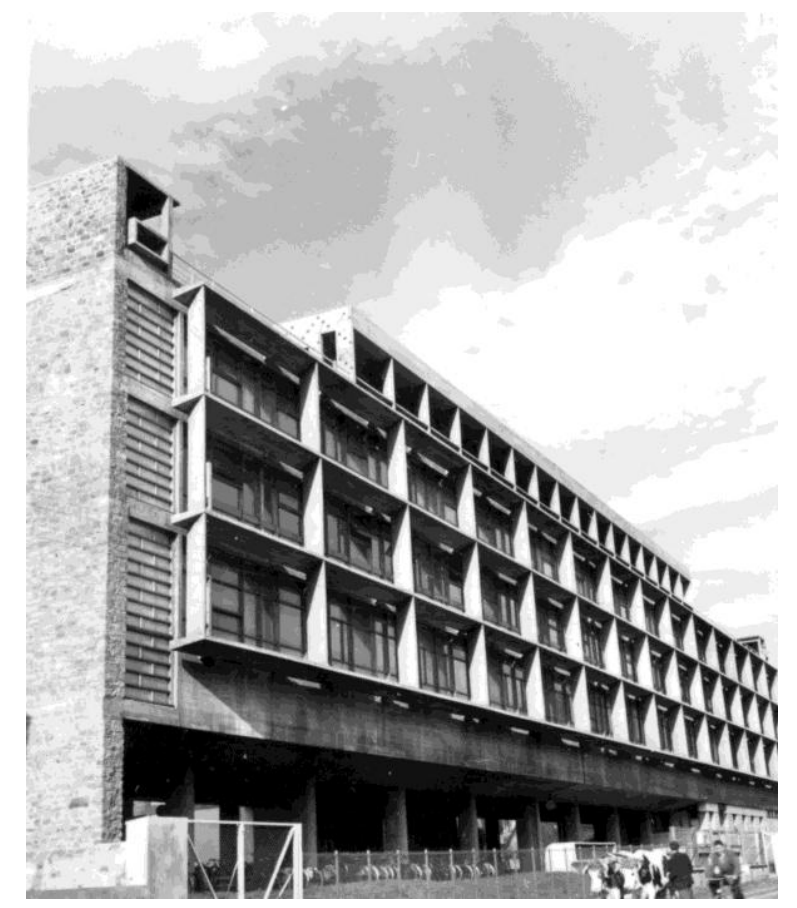

4. La fábrica de manufacturas en Saint-Dié. Fachada principal, Sudeste.

Son edificios parasol:

- La casa del Doctor Carrutchet en La Plata, Argentina (1949)

- $\quad$ El convento de La Tourette, las terrazas, Francia (1957/60)

- $\quad$ El Palacio de la Asociación de Hilanderos, Ahmedabad, India (1954)

- La Villa Shodan, Ahmedabad, India (1956)

- El Palacio de Justicia de Chandigarh, la fachada-pórtico-cajas noroeste, India (1956)

- El Secretariado de Chandigarh, las fachadas noroeste y sureste, India (1958)

- El Palacio de Asambleas de Chandigarh, fachadas pórtico suroeste y las otras, India (1956)

\footnotetext{
${ }^{36}$ El nombre de Brise-Soleil es sugerente. Deriva de Briser, romper y soleil, sol; romper el sol, briser soleil; rotura del sol. Pausa, interrupción o descanso del sol.
} 


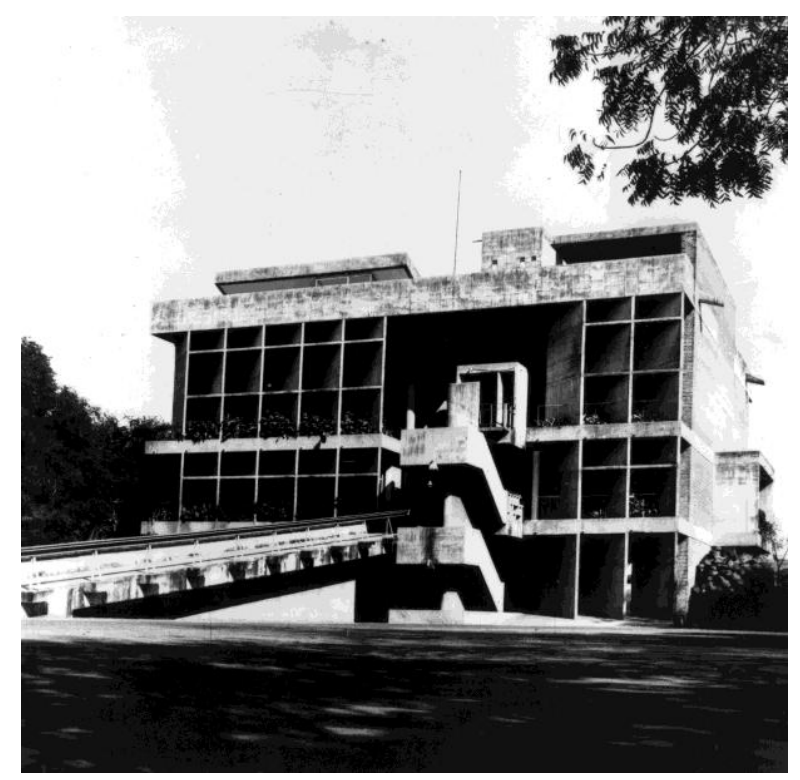

5. Palacio de la Asociación de Hilanderos. Fachada Oeste, “edificio parasol”. Buscando el Sur.

Considero esta parte de la obra de Le Corbusier básicamente griega, de interposición ${ }^{37}$, la sombra trabaja en las fachadas, en los planos-volúmenes exteriores creando una distancia entre el plano externo de luz (columnas o Brise-Soleil o edificios parasol) y la superficie proyectada (cella o fachada secundaria).

Hay también, y creo que es un tema trascedente e interesante que merece más desarrollo, unos fascinantes espacios intermedios en Le Corbusier; los interiores/exteriores o los exteriores/interiores que prolongan y descomponen los volúmenes y espacios . Las calles interiores de la Unité es un ejemplo. Pero también, y con otra trascendencia espacial, el vibrante espacio de la terraza de acogida, tras la rampa, en el Palacio de la Asociación de Hilanderos de Ahmedabad, el vacío bajo la cubierta unificadora en Palacio de Justicia de Chandigarh, la villa Shodan, el Museo de Chandigarh con el espacio patio interior-exterior o la Villa Carruchet son ejemplos de espacios exterior/interior, espacios peine, pasantes. El edificio parasol sirve también para crear distancia, alargar, aumentar la grieta, como el pórtico del palacio de la asamblea de Cahndigarh.

El segundo mecanismo es la captación. Los mecanismos de captación, los edificios cofre, son escasos en Le Corbusier, pero deslumbrantes.

Son edificios captadores:

- $\quad$ Ronchamp, la Iglesia y los tres captadores: norte, este y oeste (1950/54)

- $\quad$ El convento de La Tourette: la Iglesia y las capillas laterales inferiores (1957/60)

En La Tourette la Iglesia es un cubo de penumbra con grietas de luz y las capillas inferiores son un ejemplo de la captura de luz en diferentes orientaciones. Los captadores de Le Corbusier siguen al sol, son como heliotropos, la plantas que giran mirando al sol. En Ronchamp reutiliza sus ideas dibujadas en su viaje a Italia, del canopo de Villa Adriana, tantas veces citado. Con su vibrante luz coloreada sobre la granulada tirolesa, el trabajo con la luz es especial. Le Corbusier en este caso trabaja de forma diferente frente a la luz Suiza que frente a la continúa y uniforme luz de los trópicos o del mediterráneo, sin nubes. La luz es captada en diversas orientaciones, atrapando la vibrante luz Suiza, donde las nubes y el sol se alternan continuamente y mueven la luz de los

\footnotetext{
${ }^{37}$ El Palacio/templo griego de la Asamblea de Chandigarh es el ejemplo
} 
captadores, que vibran sobre la rugosa textura de los muros curvos. Parecen pinturas de Morandi. Le Corbusier en sus textos para Ronchamp escribe:

"Posiblemente, en la capilla de Ronchamp demostraré que la arquitectura no es problema de columnas sino de acontecimientos plásticos. Los acontecimientos plásticos no se rigen por formulas escolares o académicas, son libres e innúmeros ${ }^{, 38}$

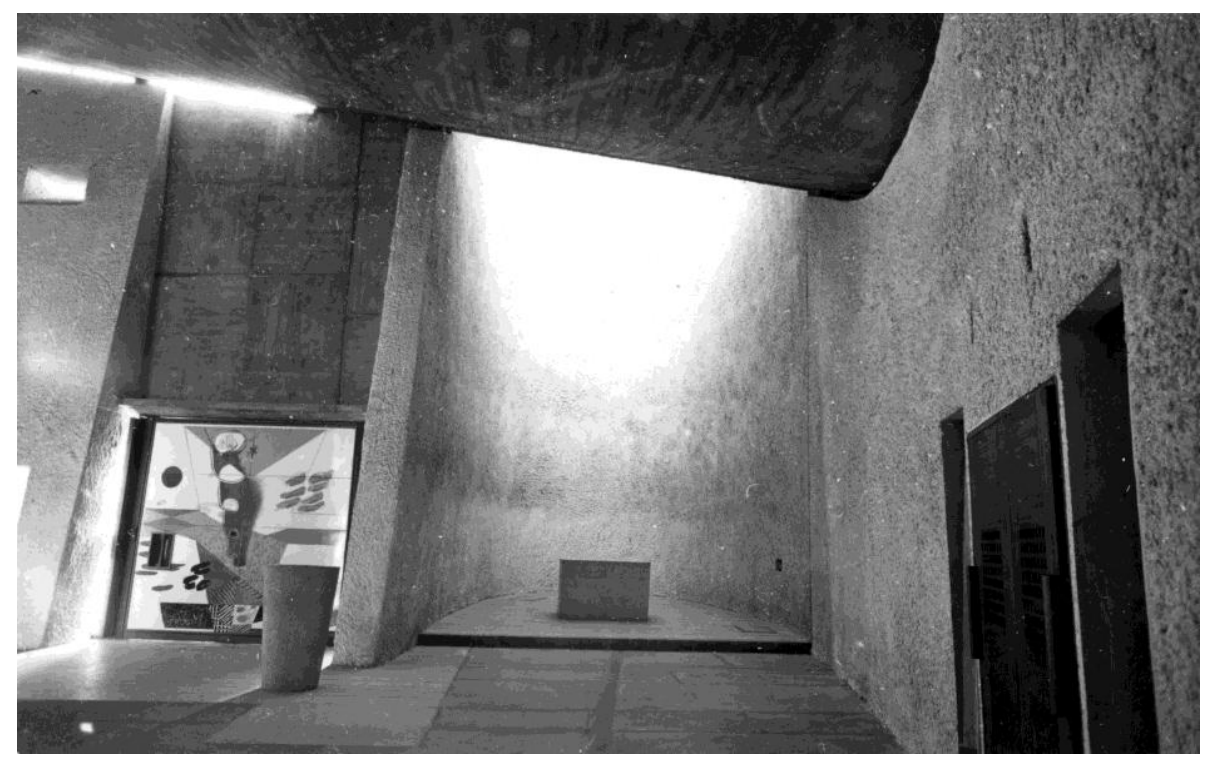

6. Capilla en Notre-Dame du Haut. Ronchamp. Capilla lateral.

Sombra y oscuridad no son lo mismo. La oscuridad es la negación, la ausencia de la luz, diferente de la sombra, su vaciado, que complementa la luz y se origina con ella. El pictograma chino 暗, Àn, significa oscuro y se forma mediante los pictogramas sonido y sol, significando "el sonido del sol". La luz emitida por el sol, que nos llega con siete minutos de retardo, puede ser entendida como un sonido, como música. La sombra es la pausa, la oscuridad el silencio.

La interposición es la brisa, el viento del sol que proyecta las sombras. La captación es el rumor del sol, que podemos levemente escuchar.

\section{Tejido y Silencio}

"Los parnasianos toman la cosa enteramente y la muestran: pero de este modo suprimen el misterio, sustraen a los espíritus el placer delicioso de creer que crean. Nombrar un objeto significa suprimir las tres cuartas partes del placer de la poesía, que consiste en adivinar poco a poco. Sugerir, este es el sueño. Y el uso perfecto de este misterio es lo que constituye el símbolo: evocar un objeto para mostrar un estado de ánimo, o bien elegir un objeto y hacer que irradie un estado de ánimo, mediante una serie de desciframientos." Stepháne Mallarmé ${ }^{39}$.

\footnotetext{
${ }^{38}$ Le Corbusier: Textos y Dibujos para Ronchamp.

${ }^{39}$ Cita Eco, en su libro "Historia de la Belleza", hablando de sugerir a Mallarmé, "Investigación sobre la evolución literaria" 1897.
} 


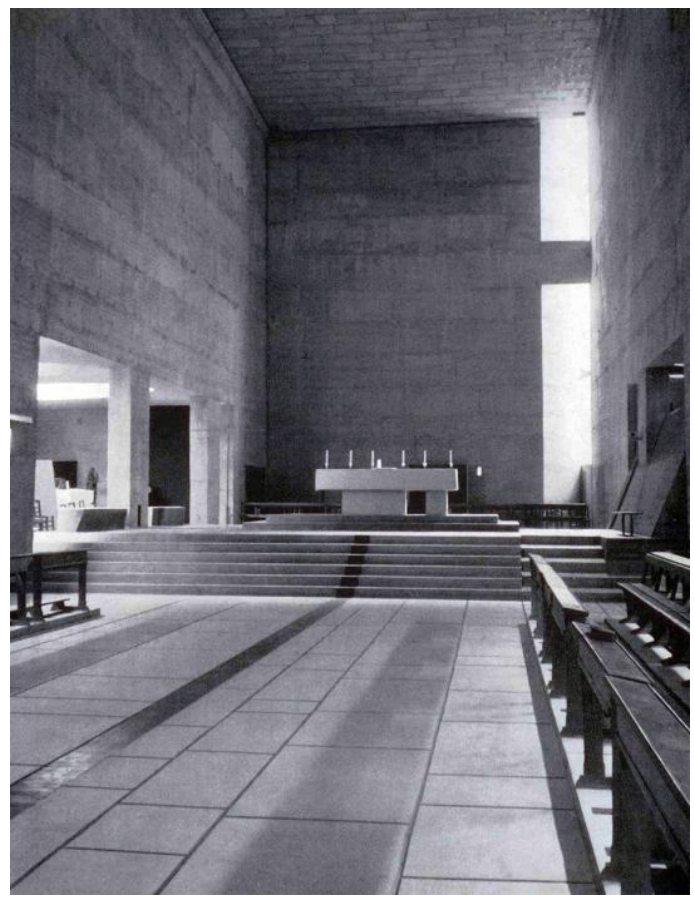

7. Convento de La Tourette. Interior de la Iglesia.

Le Corbusier heredero de la modernidad simbolista también encierra claves. Descifrar lo que significa la luz en Le Corbusier es sin duda interesante, quizás buscar lo que no dijo, sus sombras, sus silencios, escuchar su luz.

Le Corbusier utilizó el hormigón como material único, claro y diáfano, pero también utilizó la Luz (divina o humana, solar) y la sombra como material, explorando intensamente sus posibilidades. Porque la luz en Le Corbusier es arquitectura y la arquitectura de Le Corbusier es luz. Trabajó con la $L u z$ como algo físico, háptico, palpable y activo. Yo compongo con la luz, decía. La Luz y la Sombra (del mediterráneo, de los trópicos o de suiza) son palpables en Le Corbusier, densos, materiales, utilizados como un elemento (material) más de proyecto; como un muro, un cierre o un techo.

Aunque las posibilidades de trabajo con la luz son ilimitadas, su mayor hechizo, su cualidad extrema, es su intangibilidad. La seducción por lo intangible es difícil de resistir, por ello la luz, inmaterial y presencia, tiene tanto atractivo.

Construir con luz es, entonces, construir con lo intangible, sin materia. La luz es como el aire o el agua ${ }^{40}$, no tiene forma, es la superficie (el recipiente) el que le da la forma, es libre e innúmero. Tampoco tiene geometría, ni se somete al estricto control de la escuadra y cartabón; no tiene peso. La luz es materia inmaterial. Por ello lo intangible, lo que esta detrás, las presencias, sin límite o contorno definido se hacen, mediante la luz, objeto del trabajo de Le Corbusier. Sin forma, la luz es como o donde la proyectamos o recibamos. Michel Serres en su Atlas, hablando de los tejidos, decía:

"Ahora bien, entre la dureza llamada rigurosa del cristal, geométricamente ordenado, y la fluidez de las moléculas blandas y deslizantes, existe un material intermedio: velo, tela, tejido, trapo, paño, piel de cabra o de cordero, llamada pergamino, cuero despellejado de un becerro pelado o desollado, llamado vitela, papel flexible y frágil, lanas o sedas, todas las variedades planas o alabeadas en el espacio, envolturas del cuerpo o

\footnotetext{
${ }^{40}$ Como dice el Tao te King.
} 
soportes de la escritura, que pueden fluctuar como una cortina, ni líquido, ni sólido, claro, pero con algo de ambos estados. Plegable, desgarrable, extensible...topológico” Michel Serres ${ }^{41}$

La luz en la obra de Le Corbusier, es entonces, el tejido de su arquitectura. Y también el silencio. El padre Marie-Alain Couturier para expresar el origen del encargo a Le Corbusier del convento de la Tourette (1957-60), en el programa pedía Acoger cien corazones y cien cuerpos en el silencio.

Un constructor tan material como Le Corbusier, es, en sus últimos años, también un constructor de lo inmaterial, haciendo que lo invisible se torne visible, que lo ilimitado conforme los objetos, que lo ausente se haga presente, sin dimensión, sin límites y, en definitiva; que lo material surja de lo inmaterial. Construye con la luz -luz interior y luz exterior-, produce silencio; construye con el silencio. Charpentier anotaba la siguiente indicación para el Credo de la Misa de Monsieur de Mauroy.

"Producid aquí un gran silencio" 42

\section{Misterio y Búsqueda}

"Empujado por mi ávido deseo, anhelante por ver la gran mezcla de las variadas y extrañas formas hechas por la artificiosa naturaleza, dando muchos paseos entre los umbrosos acantilados, llegué a la entrada de una gran cueva, frente a la cual - al quedar muy estupefacto e ignorante de tal cosa-plegando mis riñones en arco, y quieta la cansada mano sobre la rodilla, con la derecha me hice sombra a las inclinadas y cerradas pestañas. $Y$, plegándome muchas veces aquí y allá para ver si podía discernir algo allá adentro, cosa que se me vetaba por la gran oscuridad que allí dentro había, -y después de mucho-enseguida se despertaron en mí dos cosas: miedo y deseo; miedo por la amenazadora oscura apertura, deseo de ver si allá adentro habría alguna milagrosa cosa" Leonardo da Vinci ${ }^{43}$

Para terminar el misterio, el deseo, la luz, la sombra y sobre todo, la búsqueda, de nuevo. ¿Cómo se puede entender Ronchamp ${ }^{44}$ si no es bajo una búsqueda permanente, insaciable? Le Corbusier, con su estilo perfectamente definido (La Unité o Chandigarh), se interesa por las formas naturales y cambia, para una obra, su arquitectura. ¿Y el Pabellón Philips, 1958? ¿Y su última obra, el pabellón en Zúrich, 1964? Le Corbusier, insaciable buscador, buscador de la luz, pedía a los estudiantes que mantengan los ojos abiertos, en clara actitud de permanente búsqueda. Escribía para los estudiantes:

"Y ahora, amigo mío, le ruego abra bien sus ojos. ¿Mantiene usted sus ojos abiertos? ¿Ha sido entrenado a abrir los ojos? ¿Los mantiene abiertos continuamente y útilmente? ¿Qué es lo que mira cuando va de paseo? "45

\footnotetext{
${ }^{41}$ Michel Serres, Atlas.

42 "Faites ici un grand silence", Marc-Antonie Charpentier, indicación para el Credo de la Misa de Monsieur de Mauroy. Cita de Jean Yves Patte, en su escrito "Marc Antoine Charpentier. Messe de Monsieur de Mauroy".

${ }^{43}$ Leonardo Da Vinci, Alegorías, Pensamientos, Profecías.

${ }^{44}$ Interpretada, entre otras muchas opciones, como dolmen, como cueva.

${ }^{45}$ Le Corbusier: Mensaje a los estudiantes de Arquitectura.
} 


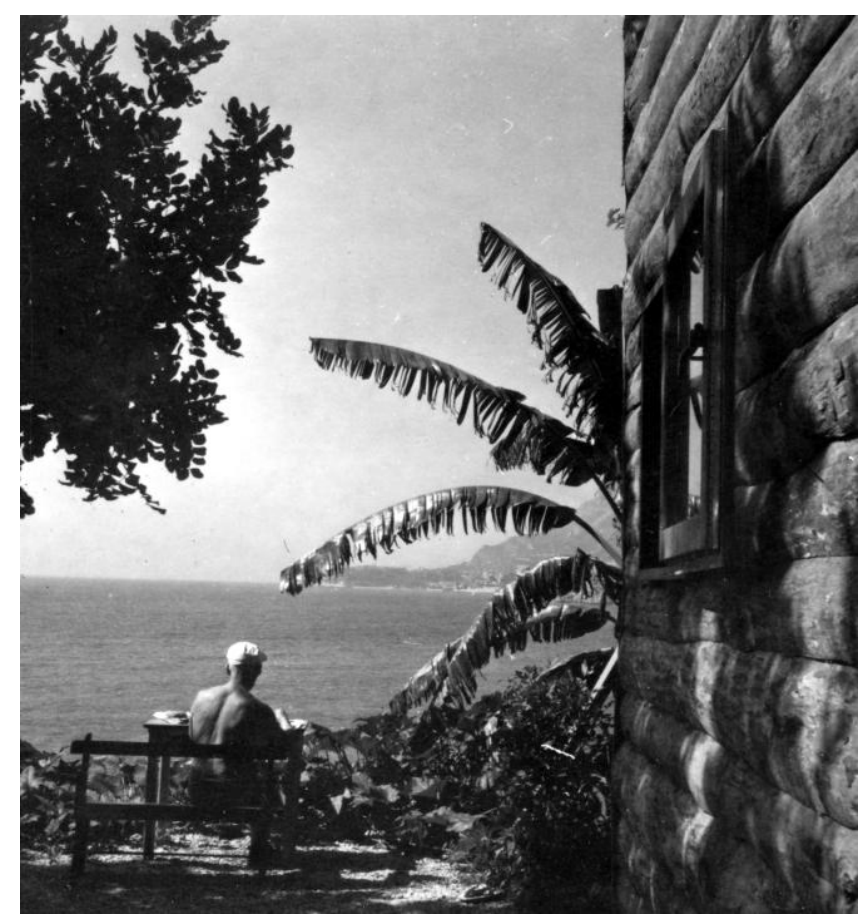

8. Le Corbusier, fuera de su cabanon en Roquebrune, Cap-Martin. Trabajando y mirando el mar.

\section{Conclusiones}

Le Corbusier, gran buscador, como el personaje doble de Stevenson, presenta -al menos- dos caras, ya que utilizó en su segunda etapa dos sistemas para trabajar con la luz: la interposición y la captación. La captación es medieval, nórdica, es la cueva, el misterio, y es también Le Corbusier barroco. La interposición es Grecia, es el mediterráneo, es la luz y la sombra, la sombra de la columna/edificio arrojada sobre el plano posterior de la cella o del edificio encerrado. Este sistema provoca, no sólo el juego de la luz y la sombra, crea también unos espacios intermedios y una "distancia" etérea entre la materialidad de sus edificios y la realidad. Y es precisamente la densidad de luz y la sombra, el material sin materia, doble, el principal elemento - de los muchos- en la obra de Le Corbusier.

Escribía Stevenson, buscador y viajero, en palabras de Henry Jekyll:

"Cada día, y desde ambos caras de mi inteligencia, la moral y la intelectual, yo me acercaba firmemente a esa verdad, por cuyo descubrimiento parcial he sido condenado a tan terrible naufragio: que el hombre no es verdaderamente uno, sino realmente dos. Digo dos, porque mi conocimiento no va más allá de ese punto.", 46

\footnotetext{
${ }^{46}$ Robert Louis Stevenson en la edición original "The Strange Case of Dr Jekyll and Mr Hyde" de 1886, en el Capítulo10; la declaración o testamento del Dr. Jeckyll: "With every day, and from both side of my intelligence, the moral and the intelectual, I thus drew steadily nearer to that truth, by whose partial discovery I been doomed to such a dreadful shipwreck: That man is no truly one, but truly two. I say two, because the state of my own knowledge does not pass beyond that point."
} 


\section{Imágenes}

Imagen 1. Crsitóbal, Ramiro: Centauros del desierto. The searchers. 1956. John Ford. Madrid: El País, 2005. DVD.

Imagen 2. Font, Domenec: La noche del cazador. The night of the hunter. Barcelona: Paidós, 1998.

Imagen 3. Pijoan, Joan: Historia del arte, Tomo I. Barcelona: Salvat, 1973.

Imagen 4. L3(6)73-141, Photographer : Lucien Hervé. Fondation Le Corbusier.

Imagen 5. L3(8)3, Photographer : Lucien Hervé

Imagen 6. L3(3)113-656, Photographer : Lucien Hervé

Imagen 7. L1(7)92-410, Photographer : Lucien Hervé

Imagen 8. L4(11)11-17, Photographer : Lucien Hervé

\section{Referencias}

Savall, Jordi. Presentación. Diego Ortiz. Recercadas del tratado de glosas. Roma 1553. Disco: ALIAVOX Heritage vol.16.

Patte, Jean Yves. "Marc Antoine Charpentier. Messe de Monsieur de Mauroy" del disco del mismo nombre del Concert Spirituel, conducido por Hervé Niquet, Glossa Cabinet Discos. Marc-Antonie Charpentier, indicación para el Credo de la Misa de Monsieur de Mauroy.

\section{Bibliografía}

Bacon, Francis: De la Sabiduría Egoísta. Madrid: Great ideas, Taurus. Santillana Editores, 2012

Baltanás, José: Le Corbusier. Promenades. Barcelona: GG, 2005

Ceinos, Pedro: Manual de escritura de caracteres chinos. Madrid: Miranguano ediciones, 1998.

Cézanne, Paul: Leer la naturaleza. Madrid: Casimiro, 2014

Da Vinci, Leonardo: Alegorías, Pensamientos, Profecías. Pensamientos. Deseo insaciable de conocer. Madrid: Gadir Editorial S.L, 2014.

Eco, Umberto: Historia de la belleza. Barcelona: Lumen, 2004.

Gamoneda, Antonio: Canción Errónea. Barcelona: Tusquets, Nuevos textos sagrados, 2012.

Jabés, Edmond: El libro de las preguntas. Libros del tiempo. Madrid: Siruela, 2006.

Jenks, Charles: Le Corbusier and the Tragic View of Architecture. Massachusetts: Harvard University Pres, 1973.

Kumar, Manjit: Quántum. Einstein, Bohr y el debate sobre la naturaleza de la realidad. Barcelona: Kairós, 2011.

Lao Zi: Tao Te King. Libro del curso y de la virtud. Madrid: Sirulea, 1998.

Le Corbusier: Hacia una arquitectura. Barcelona: Poseidón, 1977.

Le Corbusier: Catalogo exposición, 1987, Ministerio de Cultura, Madrid.

Le Corbusier: Mensaje a los estudiantes de Arquitectura. Buenos Aires: Infinito, 2008.

Le Corbusier: Textos y Dibujos para Ronchamp. Suiza: edición Jean Petit. Association ouvre de N.D. du Haut, Ronchamp, 1965.

Le Corbusier: La casa del Hombre. Barcelona: Poseidón, 1999. 
Le Corbusier: Précisions sur un état présent de lárchitecture et de lúrbanisme. Vicent-Freal et Cie, París, 1960. Paris: Éditions Crès, Collection de "L'Esprit Nouveau", 1930. Ed; castellano, Precisiones respecto a un estado actual de la arquitectura y el urbanismo, Ed. Poseidón, Barcelona, 1978.

Le May, Alan: Centauros del Desierto. (The Serchers). Madrid: Valdemar, 2013.

Mink, Janis: Duchamp. Colonia: Taschen, 2004.

Quingard, Pascal: Las escaleras de Chambord. Barcelona: Círculo de Lectores, 2013

Sabadell, Miguel Ángel: Grandes Idas de la Ciencia. Barcelona: RBA, 2012.

Schwob, Marcel: El Terror y la piedad. Buenos Aires: Libros del Zorzal, 2006.

Serres, Michel: Atlas. Madrid: Cátedra, 1995.

Steiner, George: Gramáticas de la creación. Madrid: Siruela, 2011.

Stevenson, Robert Louis: El Dr. Jekyll y Mr. Hyde. Madrid: Biblioteca Stevenson. Alianza. 2008.

Stotchita, Victor I : Breve historia de la sombra. Madrid: Siruela, 1999.

Tanizaki, Junichiro: El elogio de la sombra. Madrid: Siruela, 1994

Von Chamisso, Adelbert: La Maravillosa historia de Peter Schlemihl. Madrid: Nórdica, 2009.

Zajonc, Arthur: Capturar la luz. Girona.:Atalanta, 2015.

Zambrano, María: Claros del Bosque. Madrid. Cátedra. Letras hispánicas, 2011. 